\title{
电场方式对毛细管电泳分离 DNA 的影响
}

\author{
陈进 ${ }^{a}$ 李振庆 ${ }^{*, a, b} \quad$ 倪一 ${ }^{a}$ 刘晨晨 ${ }^{a}$ 窦晓鸣 ${ }^{a, b}$ 山口佳则 ${ }^{a, c}$

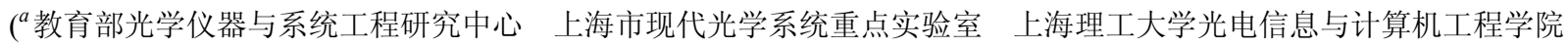 \\ 上海. 200093) \\ $\left({ }^{b}\right.$ 上海交通大学物理系光学工程研究所 上海 200240) \\ ( ${ }^{c}$ 大阪大学先进光子研究中心 大阪 565-0871)
}

\begin{abstract}
摘要 以羟乙基纤维素为笁分介质, 在直流、方波脉冲、反向脉冲电场中对 $0.1 \sim 10.0 \mathrm{kbp}$ 范围的 DNA 样品进行分离, 改变脉冲电场调制深度, 探讨电场方式对毛细管电泳分离 DNA 的影响. 研究发现, 其它实验条件一定时: (1)直流电场 下，小片段 DNA $(<1.0 \mathrm{kbp})$ 可以被有效分离, 大片段 DNA ( $>1.0 \mathrm{kbp})$ 迁移时几乎重叠在一起; (2)方波脉冲电场下，增 大调制深度可提高大片段 DNA (>1.0 kbp)分离效果, 但降低了部分小片段 DNA (0.6 1.0 kbp)的分离度; (3)反向脉冲 电场下, 可以实现 $0.1 \sim 8.0 \mathrm{kbp}$ 范围内各个 DNA 片段的有效分离, 改变调制深度会影响样本 DNA 的分离时间. 并将 反向脉冲电场应用于毛细管电泳分离 $\lambda$-DNA 的 EcoT14 I/Bgl II 限制性内切酶酶切片段. 结果表明, 反向脉冲毛细管电 泳技术具有快速、准确、重复性高等特点, 可用于宽分子量范围 DNA 片段分离.
\end{abstract}

关键词 毛细管电泳; DNA; 羟乙基纤维素; 脉冲电场; 直流电场

\section{Effect of Electric Field Modes on the Separation Performance of DNA in Capillary Electrophoresis

\author{
Chen, $\operatorname{Jin}^{a} \quad \mathrm{Li}$, Zhenqing ${ }^{*, a, b} \quad \mathrm{Ni}, \mathrm{Yi}^{a} \quad \mathrm{Liu}$, Chenchen ${ }^{a}$ \\ Dou, Xiaoming ${ }^{a, b} \quad$ Yamaguchi, Yoshinori ${ }^{a, c}$ \\ $\left({ }^{a}\right.$ Engineering Research Center of Optical Instrument and System, Ministry of Education, Shanghai Key Lab of Modern \\ Optical System, University of Shanghai for Science and Technology, Shanghai 200093) \\ ( ${ }^{b}$ Department of Physics, Optical Engineering, Shanghai Jiao Tong University, Shanghai 200240) \\ ( ${ }^{c}$ Photonics Advanced Research Center, Osaka University, Osaka 565-0871)
}

\begin{abstract}
DNA fragments ranging in size from 0.1 to $10.0 \mathrm{kbp}$ were separated by constant electric field, square-wave pulsed electric field, and inversion pulsed electric field in hydroxyethylcellulose (HEC, $1300 \mathrm{~K})$ polymer. The influence of electric field modes on the separation performance of DNA fragments was investigated when the modulation depth of pulsed electric field varied. We found that when other electrophoretic conditions were the same: (1) under constant electric field, DNA fragments can only be effectively resolved up to $1.0 \mathrm{kbp}$, whereas DNA fragments above $1.0 \mathrm{kbp}$ co-migrated; (2) under square-wave pulsed electric field, high modulation depth favors the resolution of larger DNA fragments higher than 1.0 $\mathrm{kbp}$, simultaneously the resolution of DNA fragments between 0.6 and $1.0 \mathrm{kbp}$ deteriorates with the growth of modulation depth; (3) under inversion pulsed electric field, DNA fragments ranging in size from 0.1 and $8.0 \mathrm{kbp}$ can be effectively resolved with high resolution. Furthermore, we have successfully separated the $\lambda$-DNA endonuclease fragments digested by EcoT14 I/Bgl II under inversion pulsed electric field. The results above demonstrate that inversion pulsed field capillary electrophoresis is a method with fast speed, accuracy, high reproducibility, and thus it can be applied for the separation of DNA fragments with a wide molecular range.

Keywords capillary electrophoresis; DNA; hydroxyethylcellulose; pulsed electric field; direct current electric field
\end{abstract}

\section{1 引言}

毛细管电泳(Capillary electrophoresis, CE)作为一种
高效、微量、高灵敏度及自动化的分离方法，已在医学、 生物学等领域受到广泛关注，是分离带电生物分子最有 效的技术之一 ${ }^{[1 \sim 5]}$. 近年来，毛细管电泳在分离 DNA 方

\footnotetext{
*E-mail: zhenqingli@163.com

Received May 18, 2012; published June 21, 2012.
}

Project supported by the National Natural Science Foundation of China (No. 21205078), the Innovation Program of Shanghai Municipal Education Commission (No. 13YZ073), the Shanghai Committee of Science and Technology (China) (No. 10540500700), the Cultivating of Teacher's Innovation Ability Program in University of Shanghai for Science and Technology (No. GDCX-Y-1205) and partly supported by the Leading Academic Discipline Project of Shanghai Municipal Government (No. S30502).

项目受国家自然科学基金(No. 21205078)、上海市教委科研创新项目(No. 13YZ073)、上海市科技发展基金(No. 10540500700)和上海理工大学教师创 新能力建设(No. GDCX-Y-1205), 部分受上海市重点学科项目第三期(No. S30502)资助. 
面取得了较大进展. 但是, 研究表明, 直流电场下的毛 细管电泳仅对小片段 DNA 有较好的分离效果, 而大片 段 DNA 往往重叠在一起. 为了提高大片段 DNA 的分离 效率, Carle 等 ${ }^{[6]}$ 将脉冲电场引入平板凝胶电泳, 实现了 $50 \sim 750 \mathrm{kbp}$ 较大范围内 DNA 片段的分离, 但是脉冲平 板凝胶电泳在分析 DNA 时存在耗时长、操作繁琐、自 动化程度低等不足. 1990 年 Heiger 等 ${ }^{[7]}$ 首次将脉冲电场 应用于毛细管电泳分离 DNA $(<2.0 \mathrm{kbp})$, 并取得了不 错的分离效果. 为了进一步提高脉冲毛细管电泳(Pulsed field CE, PFCE) 对 DNA 片段的分离效果, 研究人员将各 种不同形式的脉冲电场应用于毛细管电泳, 如用零积分 电场 ${ }^{[8,9]}$ 毛细管电泳时, DNA 分离度得到改善但分离时 间过长. 啁啾式脉冲电场 ${ }^{[9,10]}$ 毛细管电泳仅对小分子量 范围的 DNA 片段分离度较高. 此外, Morris 小组 ${ }^{[11]}$ 也对 直流电场与正弦脉冲混合电场分离 DNA 片段做了研究, 即在直流电场下实现小片段 DNA $(<1.0 \mathrm{kbp})$ 分离, 之 后施加脉冲电场分离大片段 DNA $(>1.0 \mathrm{kbp})$, 这种方 法虽然可以扩大 DNA 分离的范围, 但电场控制操作繁 琐，自动化程度降低. 以上表明，其它实验条件一定时， 施加电场方式不同，毛细管电泳分离相同 DNA 片段的 效率也不尽相同.
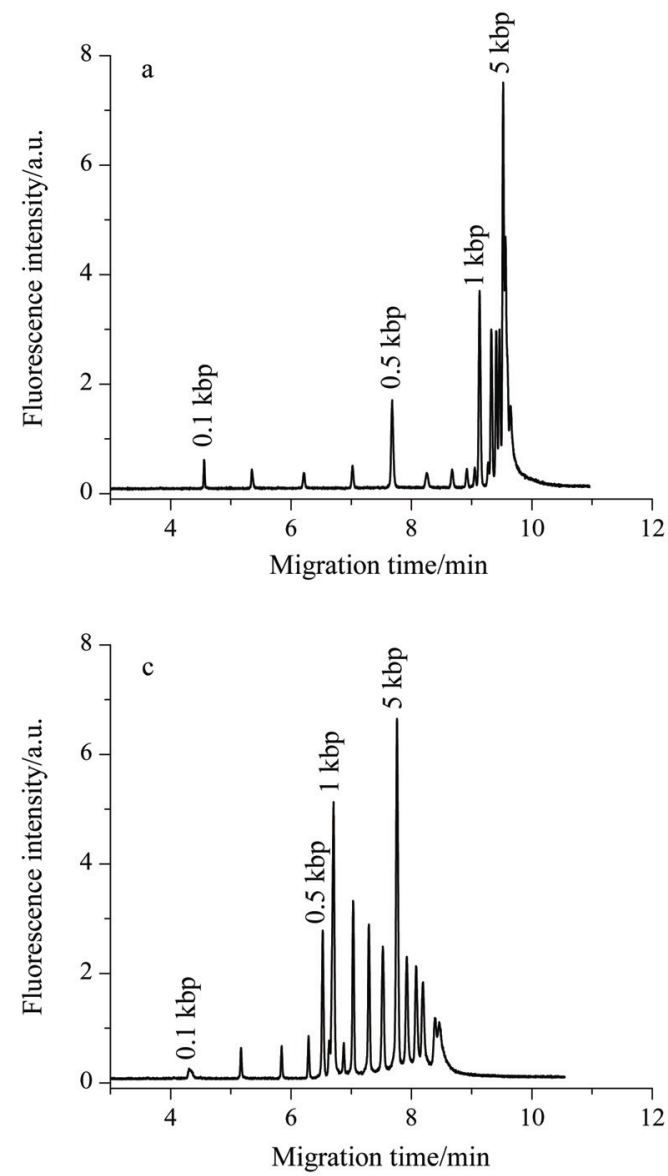

本实验以羟乙基纤维素 (Hydroxyethylcellulose, HEC) 溶液作为篮分介质, 标准 $0.1 \sim 10.0 \mathrm{kbp}$ DNA 样品 作为研究对象, 在实验室已有研究工作 ${ }^{[12,13]}$ 的基础上, 对比分析了直流、方波脉冲、反向脉冲电场对毛细管电 泳分离 DNA 的影响, 并讨论了不同电场模式下 DNA 片 段的分离特性, 其结果对实现较宽分子量范围 DNA 片 段的高效分离具有重要的实验指导意义.

\section{2 结果与讨论}

\section{1 直流毛细管电泳分离 DNA}

电泳条件如第 4.3.1 节(A)时, 直流电场毛细管电泳 分离标准 DNA 样品结果如图 1a 所示. 从电泳图谱中可 以看出, 当 DNA 片段小于 $1.0 \mathrm{kbp}$ 时, 相邻 DNA 片段 间分离度较高; 当 DNA 片段长度大于 $1.0 \mathrm{kbp}$ 时, 各个 电泳峰几乎重叠在一起，因而不能被分离。这是因为被 检测 DNA 样品在分离介质中能否被分离取决于相邻 DNA 片段间是否存在淌度差, 而迁移淌度与施加电压 和耖分介质的 Kuhn 长度有关 ${ }^{[14]}$. 当 DNA 片段在小于國 值长度 $N^{*}{ }_{k}$ 时, 淌度依据分子大小变化; 当 DNA 片段长 度大于 $N^{*}{ }_{k}$ 时, 淌度与分子大小无关, 而依赖于施加电
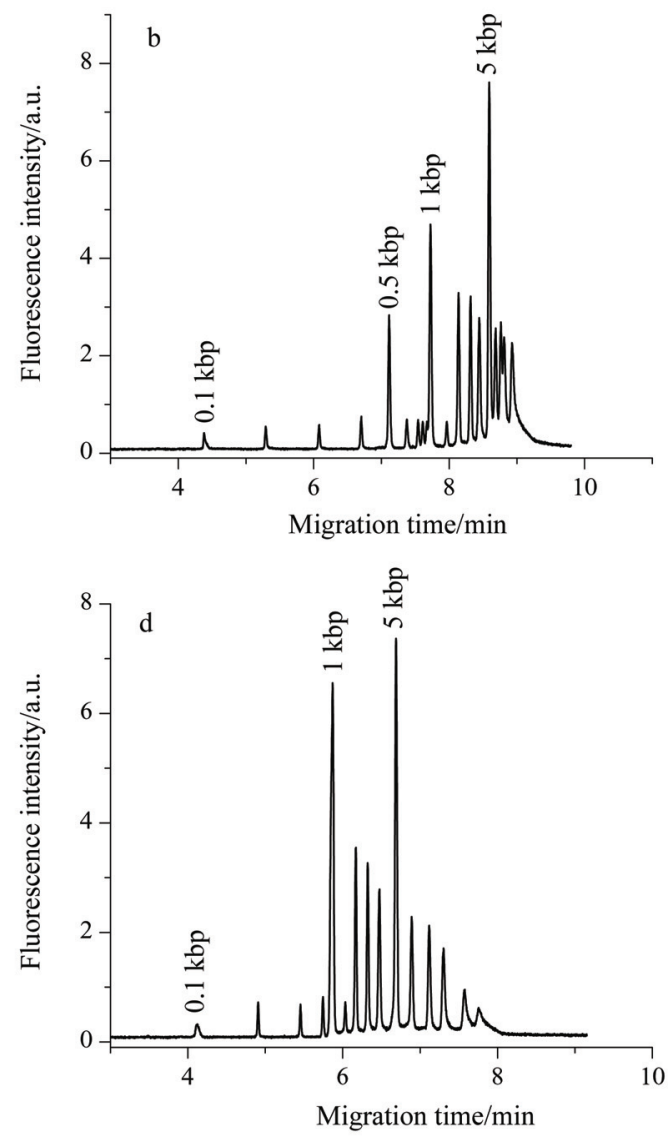

图 1 直流与方波脉冲毛细管电泳分离 DNA 时电泳图谱

Figure 1 Electropherograms of DNA by DC-CE and SW-PFCE

(a) DC-CE $(E=100 \mathrm{~V} / \mathrm{cm})$; (b) $M=100 \%$; (c) $M=150 \%$; (d) $M=200 \%$. Injection voltage: $2 \mathrm{~s}$ at $100 \mathrm{~V} / \mathrm{cm} ; \lambda_{\mathrm{ex}}=460 \sim 490 \mathrm{~nm}$, $\lambda_{\mathrm{em}}=521 \mathrm{~nm}$; Dimension of capillary: $l_{\mathrm{t}}=15 \mathrm{~cm}, l_{\mathrm{e}}=8 \mathrm{~cm}, \mathrm{ID}=75 \mu \mathrm{m}, \mathrm{OD}=360 \mu \mathrm{m}$; Detection system was enclosed in a black box 
场和篮分介质分子所形成的孔径大小. 这一现象从图 $2 \mathrm{a}$ 中也可以发现, 当 DNA 片段大于 $1.0 \mathrm{kbp}$ 时, 相邻 DNA 片段之间淌度差很小, 导致相邻 DNA 片段间的分 离度几乎为 0 (图 2b).
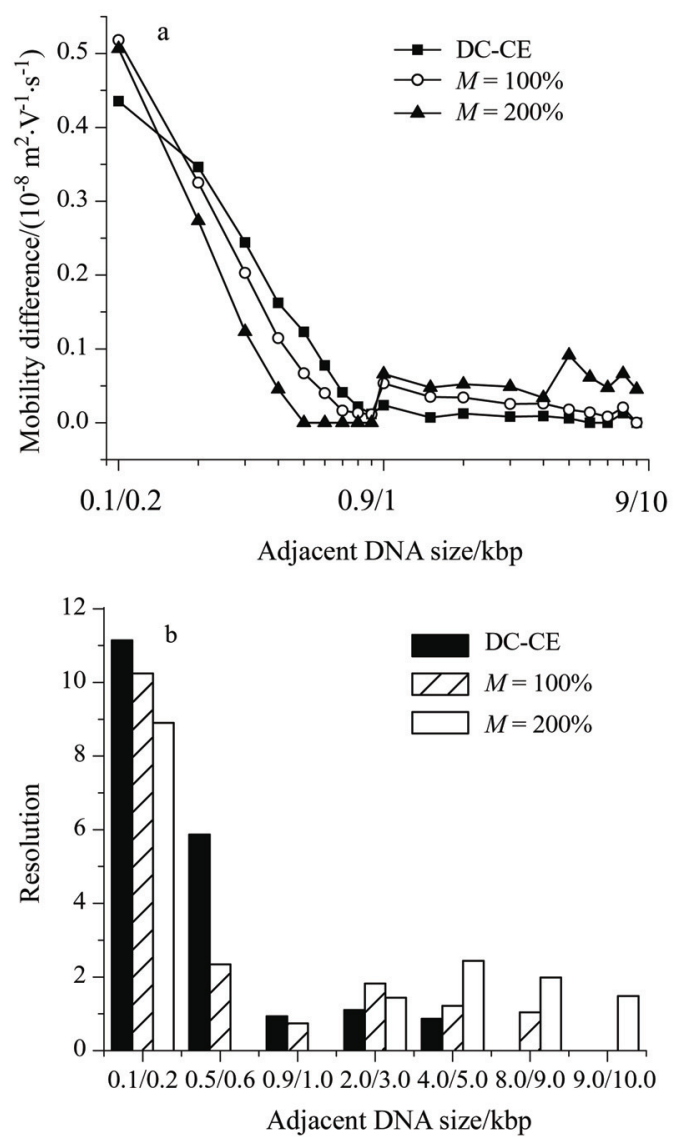

图 2 直流与方波脉冲电场下相邻 DNA 片段间淌度差与分离度 Figure 2 The separation results of adjacent DNA fragments by DC-CE and SW-PFCE

(a) Mobility difference; (b) resolution

\section{2 方波脉冲毛细管电泳分离 DNA}

图 $1 \mathrm{~b} \sim 1 \mathrm{~d}$ 是方波脉冲电场按第 4.3.2 节(A)条件分 离 DNA 标准样品的电泳图谱, 图 2 是直流与方波脉冲 电场下相邻 DNA 片段间淌度差与分离度, 结果显示: (1) 相对于直流毛细管电泳分离 DNA, 方波脉冲毛细管电 泳时, 大片段 DNA $(1.0 \sim 10.0 \mathrm{kbp})$ 相邻片段之间的淌度 差有了明显提高(图 $2 \mathrm{a}$ ), 分离度得以改善(图 2b), 分离 效果如图 $1 \mathrm{~b} \sim 1 \mathrm{~d}$ 所示. 这是由于 DNA 分子在脉冲电场 作用下, DNA 结构不断由团状结构(或球形结构)过渡到 $\mathrm{U}$ 形(或 V 形)结构 ${ }^{[15,16]}$ ，最终导致相邻大片段 DNA 之间 淌度差增大, 分离度得以提高; (2)方波脉冲电场下, 调 制深度越高, 大片段 DNA 分离效果越好(图 1c, 1d), 反 之, 调制深度越低, 对小片段 DNA 分离越有利(图 1b); (3)其它实验条件一定, 平均电场强度相同时, 调制深度 越大, DNA 在凝胶内迁移速度越快(图 1c, 1d), 这是因为
脉冲毛细管电泳时，凝胶内产生的焦耳热正比于 $V_{\mathrm{RMS}}^{2}{ }^{[17]}$, 其中 $V_{\mathrm{RMS}}^{2}=V_{\mathrm{DC}}^{2}+V_{\mathrm{AC}}^{2}$. 相同有效电场强度下, 调制深度越高, 脉冲电压导致凝胶内产生的焦耳热越大, 而焦耳热增大会降低篎分溶液的粘度 ${ }^{[18]}$, 因此 DNA 迁 移速度增大. 另外, 方波脉冲电场虽然改善了大片段 DNA $(>1.0 \mathrm{kbp})$ 的分离效率, 却降低了小片段 DNA $(<$ $1.0 \mathrm{kbp}$ )的分离度, 如图 $1 \mathrm{~b} \sim 1 \mathrm{~d}$ 所示, $0.6 \sim 1.0 \mathrm{kbp}$ 范围 内相邻 DNA 片段之间分离度随调制深度增大而降低.

\section{3 反向脉冲毛细管电泳分离 DNA}

反向脉冲电场按第 4.3.2 节(B)条件毛细管电泳分离 DNA 标准样品结果如图 3b 3d 所示. 结果表明: (1)相 对于直流毛细管电泳技术(图 3a), 反向脉冲电泳可以有 效改善 3.0 9.0 kbp 大片段 DNA 分子之间的分离效果, 提高了>1.0 kbp 区间 DNA 片段的分离度; (2)相对于方 波脉冲毛细管电泳, 反向脉冲电场条件下, $0.3 \sim 1.0 \mathrm{kbp}$ DNA片段之间淌度差得到有效增加(图 4a), 从而分离度 得到有效改善(图 4b), 弥补了方波脉冲电场分析宽范围 DNA 样品时小片段 DNA $(0.6 \sim 1.0 \mathrm{kbp})$ 分离度降低的缺 陷；(3)反向脉冲电场条件下，随着调制深度的增大，分 离时间缩短，这是因为调制深度增大，其对应的有效分 离电压也随之增大, DNA 片段所受驱动力增大, 因而迁 移速率变快; (4)较方波脉冲毛细管电泳技术, 反向脉冲 电场下样品分离时间增加, 这是由于反向脉冲电场时平 均电压低于方波脉冲电场时有效电压所致(1500 V); (5) 相同的有效电压 $(900 \mathrm{~V})$ 时，反向脉冲电场较直流电场 下毛细管电泳分离标准 DNA 片段效率明显提高(图 3a, 图 3c).

\section{4 反向脉冲毛细管电泳应用分离 $\lambda$-DNA 限制性片段}

对比直流恒定电场、方波脉冲电场及反向脉冲电场 下毛细管电泳分离 $0.1 \sim 10.0 \mathrm{kbp}$ DNA 样品分离结果, 可以发现，反向脉冲毛细管电泳在分离宽分子量范围 DNA 片段时分离效果较好. 为此, 我们在 $0.4 \% \mathrm{HEC}$ $(1300 \mathrm{~K})$ 笁分溶液中采用反向脉冲毛细管电泳 $\left(V_{\mathrm{f}}=V_{\mathrm{b}}=\right.$ $1500 \mathrm{~V}, t_{\mathrm{f}}=30 \mathrm{~ms}, t_{\mathrm{b}}=10 \mathrm{~ms}$ ) 分离 EcoT14 I/Bgl II 限制 性内切酶酶切 $\lambda$-DNA 片段(图 5). 由图显示, $0.1 \sim 10.0$ $\mathrm{kbp}$ DNA 片段在脉冲电场下基本可以实现宽分子量 DNA 片段分离, 对于 60/74 和 415/421 DNA 片段, 若要 实现完全分离, 需进一步优化反向脉冲电场条件.

\section{3 结论}

在带电生物分子分析领域, 如何实现宽范围、大片 段 DNA 分子的快速高效毛细管电泳分离是一个技术难 题. 本工作将直流电场、方波脉冲电场以及反向脉冲电 场三种不同电场模式的毛细管电泳技术用于 $0.1 \sim 10.0$ kbp DNA 标准样品的分离, 研究发现: (1)直流电场下, 小片段 DNA $(<1.0 \mathrm{kbp})$ 可以被有效分离, 大片段 DNA 

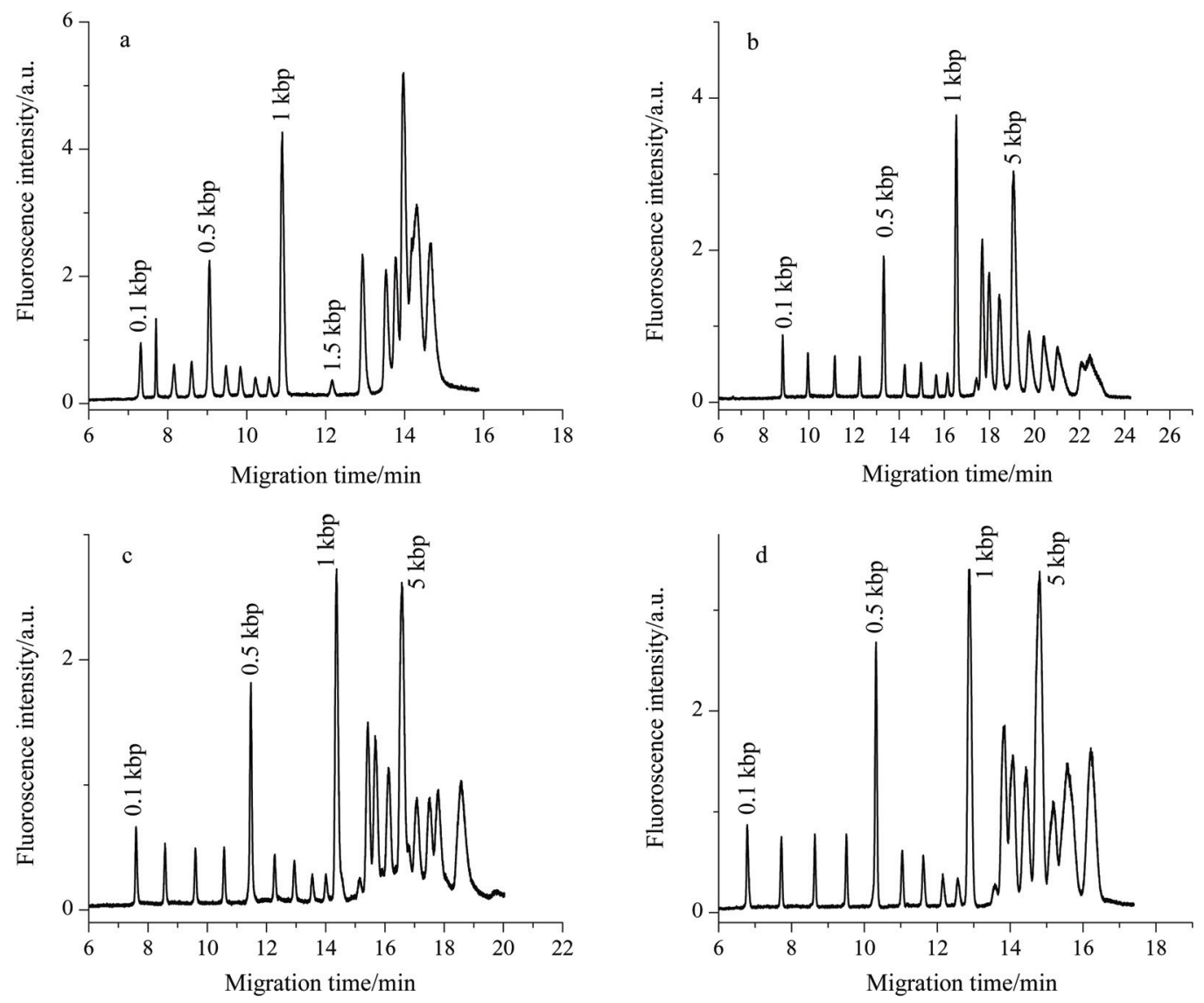

图 3 直流与反向脉冲毛细管电泳分离 DNA 时电泳图谱

Figure 3 Electropherograms of DNA in DC-CE and IFCE

(a) DC-CE $(E=60 \mathrm{~V} / \mathrm{cm})$; (b) $M=3$; (c) $M=4$; (d) $M=5$. Other conditions are the same as those in Figure 1
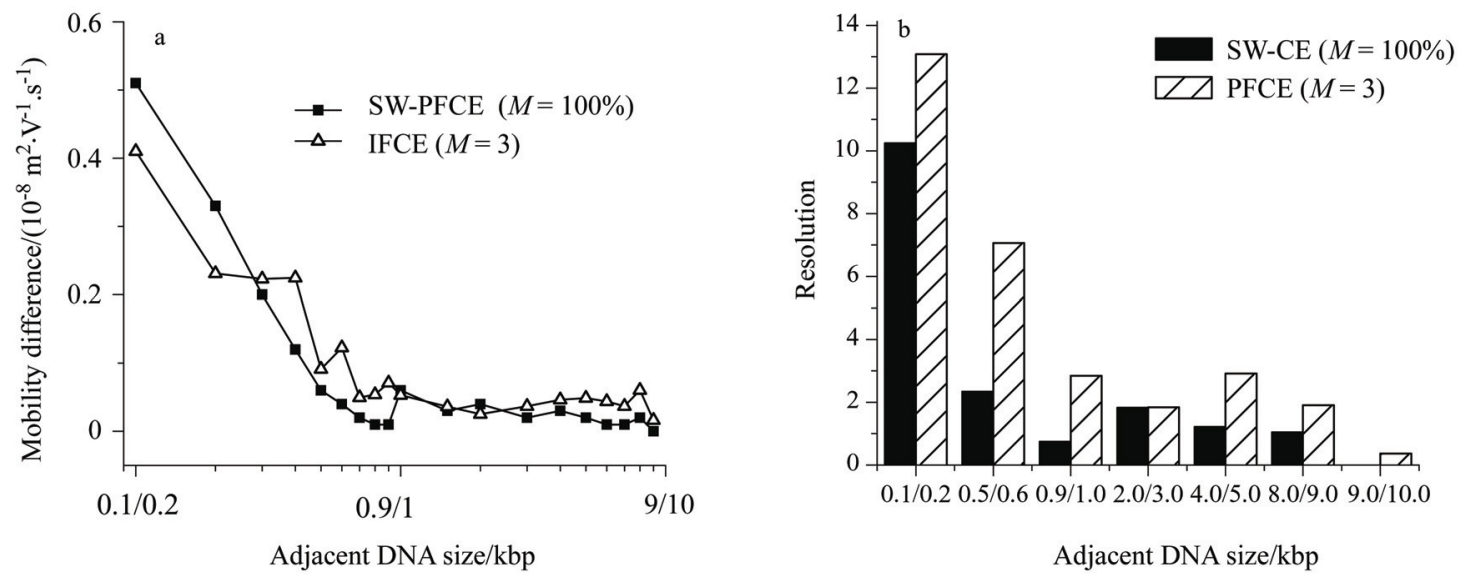

图 4 方波脉冲与反向脉冲电场下相邻 DNA 片段间淌度差与分离度

Figure 4 The separation results of adjacent DNA fragments by SW-PFCE and IFCE (a) Mobility difference, (b) resolution

$(>1.0 \mathrm{kbp})$ 迁移时几乎重叠在一起; (2)以降低部分小片 段 DNA 分离度为代价, 方波脉冲电场可以有效提高大 片段 DNA 的分离效率; (3) 反向脉冲毛细管电泳技术在 分离大片段 DNA 样品时, 既具有直流电场毛细管电泳 能够高效分析小片段 DNA 的优点, 也兼备了脉冲电场
毛细管电泳分离大片段 DNA 的优势，是一种理想的脉 冲毛细管电泳技术. 因此, 反向脉冲毛细管电泳在分析 大片段 DNA 时具有良好的应用前景, 对分析其它带电 生物分子也具有重要的指导意义. 


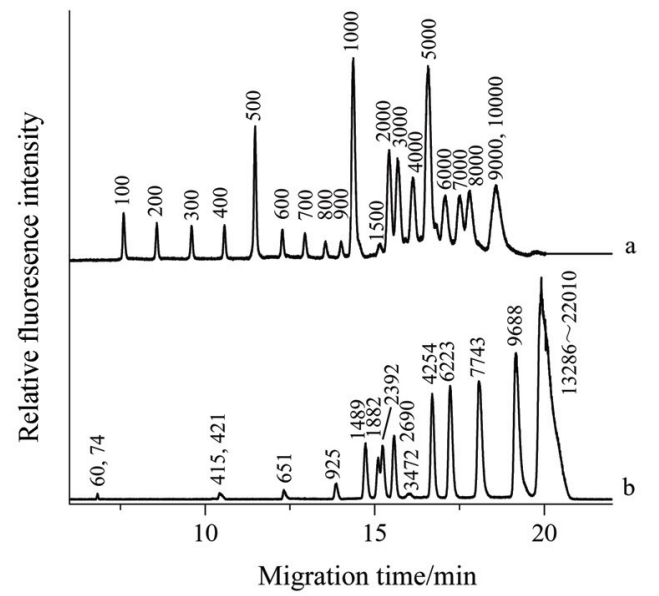

图 5 反向脉冲毛细管电泳分离(a)标准 DNA 样品和(b)限制性内切酶 EcoT14 I/Bgl II 酶切 $\lambda$-DNA 片段时电泳图谱

Figure 5 Electropherograms of (a) DNA ladder and (b) $\lambda$-DNA fragments digested by EcoT14 I/Bg1 II restriction enzyme by IFCE Other conditions are the same as those in Figure 1

\section{4 实验部分}

\section{1 实验器材与条件}

羟乙基纤维素 HEC (1300 K)(美国 Sigma 公司), SYBR Green I(美国 Invitrogen 公司), 10× Tris-borateEDTA (TBE)(美国 Bio-Rad 公司), 0.1 与 $1.0 \mathrm{kbp} \mathrm{DNA}$ ladder 样品(日本 Takara 株式会社)在 $0.5 \times \mathrm{TBE}$ 缓冲液 中混合成浓度为 $16 \mu \mathrm{g} / \mathrm{mL}$ 的标准样品, 之后将其保存 于 $-20{ }^{\circ} \mathrm{C}$ 的低温环境中. $\lambda$-EcoT14 I/Bgl II digest(日本 Takara 株式会社).

采用实验室自制毛细管电泳系统 ${ }^{[12,13,19,20]}$, 主要构 造部件如下: 石英毛细管柱(内径外径分别为 75 和 360 $\mu \mathrm{m}$ ) (美国 Polymimicro Technologies)总长度 $15 \mathrm{~cm}$, 有 效长度 $8 \mathrm{~cm}$, 倒置显微镜 IX71(日本 Olympus); MODEL $610 \mathrm{E}$ 高压电源 (美国 Trek); 脉冲波形及参数通过 Labview(美国 National Instrument)程序控制; 录灯光源 发出的光经滤光片 U-MWIB-3(日本 Olympus)过滤后产 生波长为 $460 \sim 495 \mathrm{~nm}$ 的激发光, 荧光经 $60 \times$ 物镜 PlanApo/IR(日本 Olympus)之后收集于光电倍增管 R928(日本 Hamamatsu Photonics), 最后由数据采集卡 PCI-6024E(美国 Austin 公司)处理. 为降低电渗流, 本实 验根据文献[21，22]的方法，采用线性聚丙烯酰胺对毛 细管内壁做了改性处理. DNA 样品以 $100 \mathrm{~V} / \mathrm{cm}$ 电动进 样于毛细管, 进样时间 $2 \mathrm{~s}$, 整个检测过程在常温下的暗 室中进行.

\section{2 脉冲电场方式}

\subsection{1 方波脉冲电场}

方波脉冲电场主要涉及到以下四个参数: 正向脉冲 电压 $V_{\mathrm{f}} 、$ 负向脉冲电压 $V_{\mathrm{b}}$ 、正向脉冲时间 $t_{\mathrm{f}}$ 及负向脉冲 时间 $t_{\mathrm{b}}$, 它们共同决定了脉冲毛细管电泳的平均电压

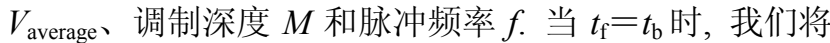
方波脉冲电场下的毛细管电泳定义为方波脉冲毛细管 电泳. 方波脉冲毛细管电泳分离 DNA 时, 平均电压 $V_{\text {average }}$ 决定了 DNA 在迁移时所受到的驱动力大小, 其 定义为:

$$
V_{\text {average }}=\left(V_{\mathrm{f}} t_{\mathrm{f}}-V_{\mathrm{b}} t_{\mathrm{b}}\right) /\left(t_{\mathrm{f}}+t_{\mathrm{b}}\right)
$$

调制深度 $M$ 反映了脉冲电压 $V_{\mathrm{f}}$ 与平均电压 $V_{\text {average }}$ 的对 比关系，定义为:

$$
M=\left(V_{\mathrm{f}}-V_{\text {average }}\right) / V_{\text {average }} \times 100 / \%
$$

脉冲频率决定了 DNA 在毛细管内正向和反向运动时间 的长短, 定义为:

$$
f(\mathrm{~Hz})=1000 /\left(t_{\mathrm{f}}+t_{\mathrm{b}}\right)
$$

依据直流电场下电泳淌度 $\mu^{[23]}$, 我们将脉冲电场下淌度 定义为:

$$
\mu=l_{\mathrm{t}} l_{\mathrm{e}} /\left(t \times V_{\text {average }}\right)
$$

其中 $l_{\mathrm{t}}$ 为毛细管总长度, $l_{\mathrm{e}}$ 为毛细管有效长度, $t$ 为电泳峰 对应分离时间.

\subsection{2 反向脉冲电场}

为区别于方波脉冲电场，我们将正向电压 $V_{\mathrm{f}}$ 与反向 脉冲电压 $V_{\mathrm{b}}$ 相等，正向脉冲与反向脉冲时间不同，即 $V_{\mathrm{f}}=V_{\mathrm{b}}, t_{\mathrm{f}} \neq t_{\mathrm{b}}$ 时的电场定义为反向脉冲电场, 此时对应 为反向脉冲毛细管电泳, 其平均电压 $V_{\text {average }}$ 调制深度 $M$ 及淌度 $\mu$ 分别定义为:

$$
\begin{aligned}
& V_{\text {average }}=V\left(t_{\mathrm{f}}-t_{\mathrm{b}}\right) /\left(t_{\mathrm{f}}+t_{\mathrm{b}}\right) \\
& M=t_{\mathrm{f}} / t_{\mathrm{b}} \\
& \mu=l_{\mathrm{t}} l_{\mathrm{e}} /\left[\left(V_{\mathrm{f}} t_{\mathrm{f}}+V_{\mathrm{b}} t_{\mathrm{b}}\right) /\left(t_{\mathrm{f}}+t_{\mathrm{b}}\right)\right]
\end{aligned}
$$

\section{3 实验方法}

\subsection{1 直流电场下毛细管电泳分离大片段 DNA 分子}

直流电场毛细管电泳(Direct current CE, DC-CE) 分 离 DNA 标准样品, 实验条件如下:

(A) 背景电解液: $0.5 \times \mathrm{TBE}+0.5 \% \mathrm{HEC}+1 \times \mathrm{SYBR}$ Green I, 电场强度: $100 \mathrm{~V} / \mathrm{cm}$.

(B) 背景电解液: $0.5 \times \mathrm{TBE}+0.3 \% \mathrm{HEC}+1 \times \mathrm{SYBR}$ Green I, 电场强度: $60 \mathrm{~V} / \mathrm{cm}$.

4.3.2 方波与反向脉冲电场下毛细管电泳分离大片段 DNA 分子

依据我们前期工作 ${ }^{[12,13]}$, 选择方波与反向脉冲电场 下毛细管电泳分离 DNA 标准样品时实验条件分别如下:

(A)方波脉冲毛细管电泳(Square wave pulsed field capillary electrophoresis, SW-PFCE)时背景电解液为: 0.5 $\times \mathrm{TBE}+0.5 \% \mathrm{HEC}+1 \times \mathrm{SYBR}$ Green I, 脉冲电场条件: 平均电压 $1500 \mathrm{~V}$ 、脉冲频率 $50 \mathrm{~Hz}$ 、调制深度 $100 \%$ $200 \%$, 不同调制深度时对应正向脉冲电压 $V_{\mathrm{f}}$ 与负向脉 冲电压 $V_{\mathrm{b}}$ 如图 6a 所示.

(B) 反向脉冲毛细管电泳 (Inversion field capillary electrophoresis, IFCE) 时背景电解液为: $0.5 \times \mathrm{TBE}+0.3 \%$ $\mathrm{HEC}+1 \times \mathrm{SYBR}$ Green I，脉冲电场条件：调制深度 3 
5 , 对应平均电压分别为 750,900 和 $1000 \mathrm{~V}$, 不同调制 深度时对应的正向脉冲时间 $t_{\mathrm{f}}$ 与负向脉冲时间 $t_{\mathrm{b}}$ 如图 $6 \mathrm{~b}$ 所示.
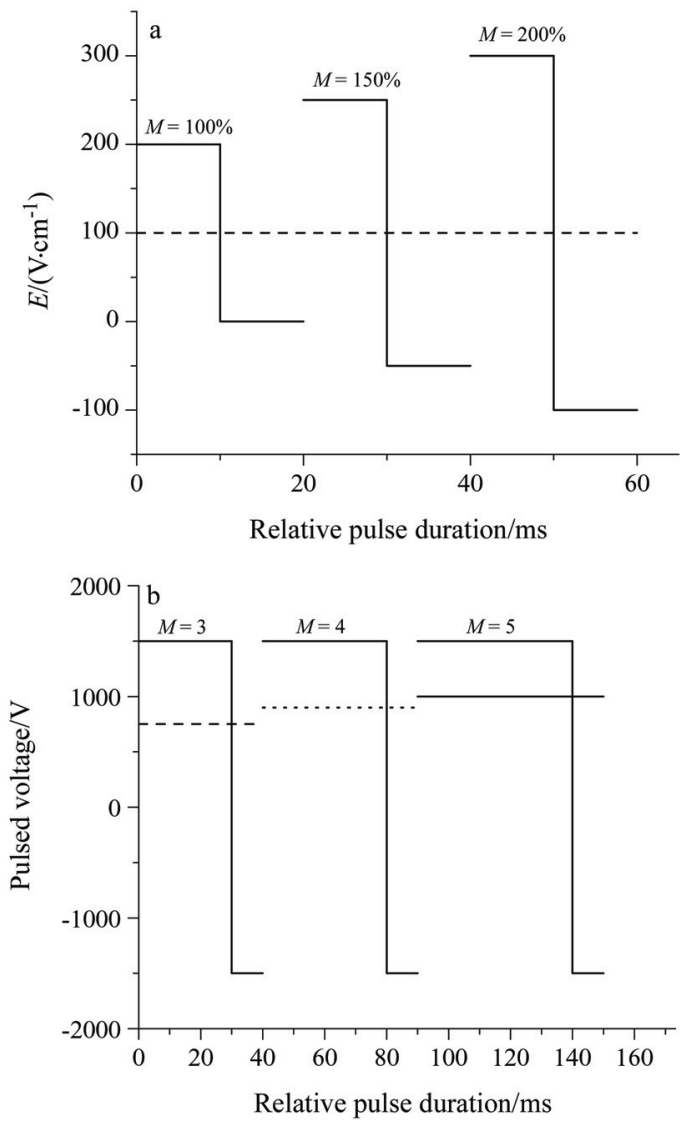

图 6 方波脉冲(a)和反向脉冲(b)电场示意图

Figure 6 Schemes of electric field in SW-PFCE (a) and IFCE (b)

\section{References}

[1] Woolley, A. T.; Hadley, D.; Landre, P.; Demello, A. J.; Mathies, R. A.; Northrup, M. A. Anal. Chem. 1996, 68, 4081.

[2] Wang, R.; Jia, Z.-P.; Dong, Y.-L.; Chen, X.-G.; Xie, H. Acta Chim. Sinica 2010, 68, 269. (王荣, 贾正平, 董亚蕾, 陈兴国, 谢华, 化 学学报, 2010, 68, 269.)

[3] Wang, Q.; Xu, X. Acta Chim. Sinica 2004, 62, 66. (王前, 许旭, 化 学学报, 2004, 62, 66.)

[4] Wang, Q.; Xu, X.; Dai, L. X. Chin. J. Chem. 2006, 24, 1766.

[5] Zhang, Y. X.; Zhang, Z. J.; Yang, F. Chin. J. Chem. 2008, 26, 489.

[6] Carle, G. F.; Olson, M. V. Nucleic Acids Res. 1984, 12, 5647.

[7] Heiger, D. N.; Cohen, A. S.; Karger, B. L. J. Chromatogr. 1990 $516,33$.

[8] Kim, Y.; Morris, M. D. Electrophoresis 1996, 17, 152.

[9] Sudor, J.; Novotny, M. Proc. Natl. Acad. Sci. U. S. A. 1993, 90 9451

[10] Morris, M. D.; Schwinefus, J. J.; de Carmejane, O. Methods Mol. Biol. 2001, 162, 307.

[11] Kim, Y.; Morris, M. D. Anal. Chem. 1994, 66, 3081.

[12] Li, Z.; Dou, X.; Ni, Y.; Sumitomo, K.; Yamaguchi, Y. J. Sep. Sci. 2010, 33, 2811

[13] Li, Z.; Dou, X.; Ni, Y.; Yamaguchi, Y. Anal. Bioanal. Chem. 2011 $401,1661$.

[14] Todorov, T. I.; Morris, M. D. Electrophoresis 2002, 23, 1033.

[15] Shi, X.; Hammond, R. W.; Morris, M. D. Anal. Chem. 1995, 67, 1132.

[16] Shi, X.; Hammond, R. W.; Morris, M. D. Anal. Chem. 1995, 67, 3219.

[17] Kim, Y.; Yeung, E. S. Electrophoresis 1997, 18, 2901.

[18] Siles, B. A.; Anderson, D. E.; Buchanan, N. S.; Warder, M. F. Electrophoresis 1997, 18, 1980.

[19] Li, Z.; Dou, X.; Ni, Y.; Sumitomo, K.; Yamaguchi, Y. Electrophoresis 2010, 31, 3531.

[20] Li, Z.; Dou, X.; Ni, Y.; Chen, Q.; Cheng, S.; Yamaguchi, Y. J. Chromatogr. A 2012, 1229, 274.

[21] Schmalzing, D.; Piggee, C. A.; Foret, F.; Carrilho, E.; Karger, B. L. J. Chromatogr. A 1993, 652, 149.

[22] Hjerten, S. J. Chromatogr. A 1985, 347, 191

[23] Slater, G. W.; Desruisseaux, C.; Hubert, S. J. Methods Mol. Biol. 2001, 162, 27. 